DEMOGRAPHIC

DEPENDENCY RATIOS

The process of ageing of populations is not limited to high income countries. The "elderly dependency ratio" (the relation of old persons (65 years and above) to the economically active population (between 15 and 64) is on a steady increase even in A frica. However, the - actual and future - elderly dependency ratios in poor countries are quite a bit smaller than those in rich countries.

\section{Facts and figures}

When one looks to single countries (a selection is presented in the Table below) it is noticeable that the elderly dependency ratios cover a wide range. The projected values for 2050 range from Turkey (lowest value, 30 percent) to I taly (highest value, 69 percent). Other countries with comparatively low elderly dependency ratios in 2050 are D enmark and $U$ nited States ( 35 percent), Finland (38 percent), United Kingdom and Sweden (39 percent). R ather high dependency ratios are projected also for Spain ( 66 percent), G reece and Japan (56 percent) and A ustria (52 percent).

\section{Increases of the dependency ratios}

The future demographic burden is not only characterised by the - actual or projected - level of the elderly dependency ratio but also by its change over time. Here also we observe considerable dif-

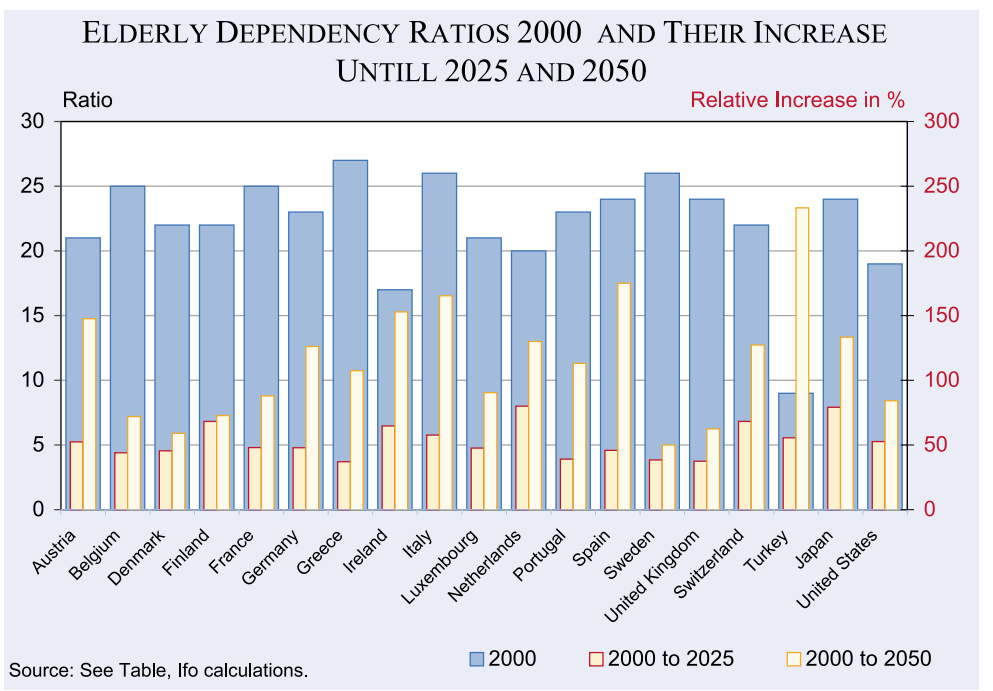

ferences between countries and group of countries (see Figure). When we look first at the development until 2025, the dependency ratio in A frica increases only by around 16 percent (from 6 percent to 7 percent), while the World Total increases by 36 percent and the OECD total by 52 percent. Looking again at some single countries, the increase ranges from 37 percent ( $G$ reece) to 80 percent ( $\mathrm{N}$ etherlands). 0 ther countries with relatively low increases of the elderly dependency ratio up to 2025 are the U nited K ingdom (37.5 percent), Sweden 38.5 percent) and Portugal (39 percent). $\mathrm{R}$ ather high increases can also be observed in Japan ( 79 percent) and in Finland (68 percent).

Considering now the change within the 50-years period between 2000 and 2050, the relative increases of the elderly dependency ratio become enormous. The least increases are projected to occur in Sweden (50 percent), Denmark (59 percent), Belgium (72 percent) and Finland ( 73 percent), while the highest increases are projected for Turkey (233 percent), Spain (175 percent) and A ustria (148 percent).

\section{Total and weighted dependency ratios}

The Table shows not only the "elderly dependency ratio" but also provides information on the "total dependency ratio" and on the "needs weighted dependency ratio". The total dependency ratio relates not only the elderly to the active population, but the elderly plus the young (0-14 years) to the active population. The needs weighted dependency ratio is a refined measure of the total dependency ratio. It takes into consideration (or assumes) that the demographic burden of children is lower than of elderly persons and adjusts the measure accordingly by weighting.

Comparing the elderly dependency ratio to the needs weighted dependency ratio for 2050 we notice that in many country groups (e.g. A frica, A rab countries, $A$ sia) the needs weighted dependency ratios are higher than the (narrower) measure of the elderly dependency ratios (which are relatively low there). This is also true for the world as a whole. In these cases, obviously, the demographic burden (of the 


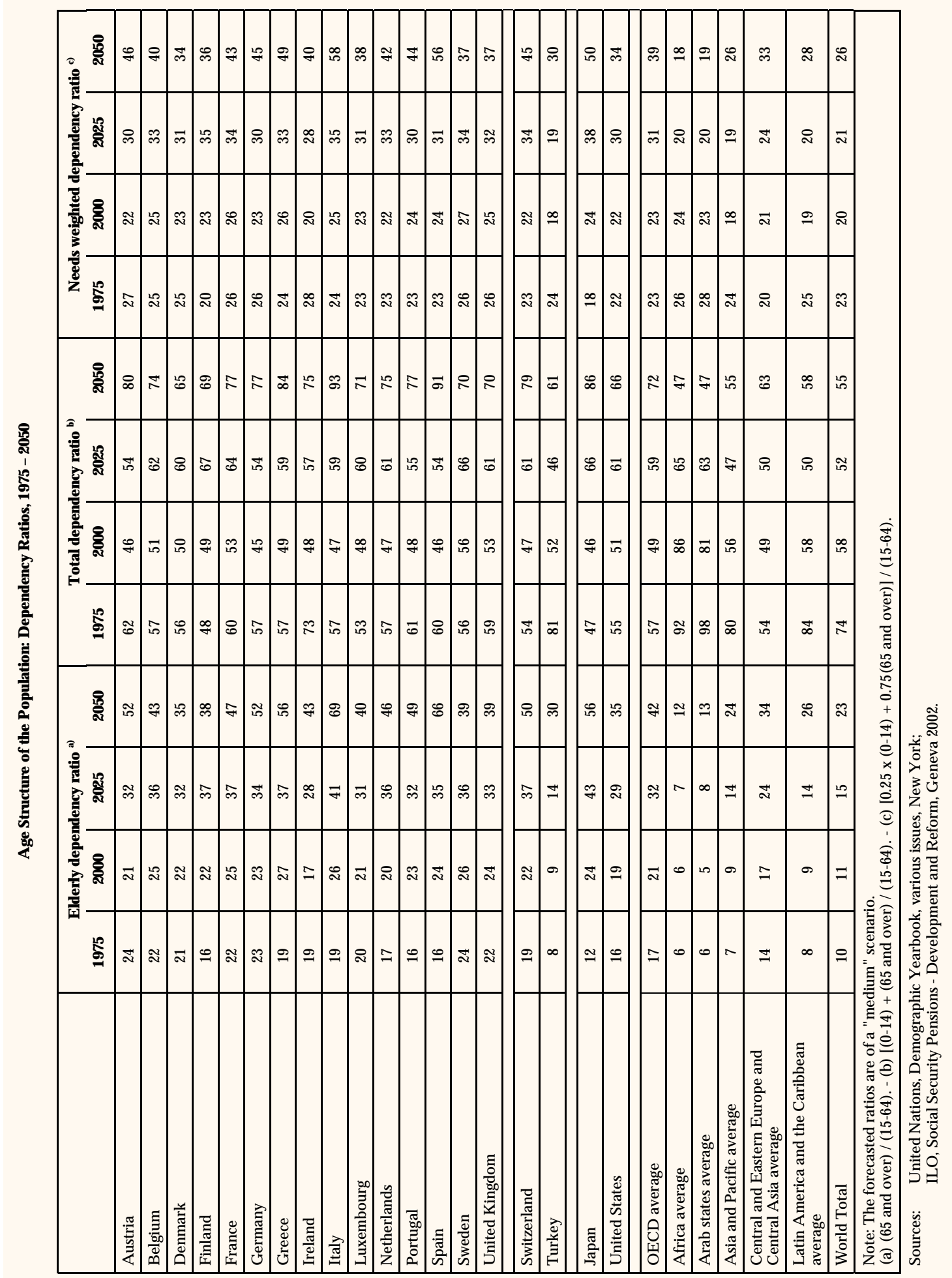

year 2050) stems more from the younger than from the older population. In the OECD, and specifically in the European countries, however, the picture is quite different. Here the needs weighted dependency ratios (again for 2050) are lower than the elderly dependency ratios (which are relatively high here).
That means, generally, that (nearly all) societies with a high old-age demographic burden (the rich countries) have - or will have - a low young-age demographic burden, so that their total (or weighted total) burden is not quite so high. A nd it means that societies with a low old-age demographic burden (the poor countries) have - or will have - a 
high young-age demographic burden, so that their total (or weighted total) burden is not quite so low.

\section{A good and a bad message}

The figures contain a good and a bad message. The bad message is that - in what society soever you might live in the world - the demographic burden will keep rising for the next half century. But not only are levels and rates of increase of the dependency ratios high, they also differ quite considerably between countries. $A$ nd this is the basis for the good message.

The demographic burden must always be shouldered by those who are economically active - but the demographic burden of one society is not necessarily to be shouldered by the active population of that same society. The burden can (temporarily) be shifted from one society to another. This can be effectuated by means of the international capital markets and by corresponding flows of real goods and services.

A society with an unfavourable projection of its demographic burden (society A) can save (more) and invest their money in financial and other assets of societies of a more favourable demographic projection (B). Society $A$ is, e.g., going to have less children and the parents can, thus, save more. $D$ uring this period country $A$ has current account surpluses. When the savers of country A become old their investment is honoured with interest payment and repayment of the principal. During this period country $A$ has current account deficits. This is all the more possible the more differentiated levels and increase rates of the dependency ratios are.

U nfortunately, there is one problem and one condition connected with this good message. The problem is that the countries with relatively low demographic burdens are mainly economically weak and will not be able to offer significant investment opportunities, nor to honour in a credible way the bonds they have sold to the demographically older countries. But there also are exceptions: The $\mathrm{U}$ nited States and the U nited Kingdom, e.g., are economically strong and have relatively good demographic projections.

A nd there is a condition. The temporary shifting of demographic burdens by means of international capital flows is - generally speaking - independent of the type of old-age financing which prevails in a certain country. It may happen with a pay-as-yougo as well as with a funded system. But a pay-asyou-go system is implausible to lead to higher savings - because people tend to think that their pensions are unrelated to their (own) number of children. A nd while they economise on costs for raising children they might increase their consumption. By contrast, a funded system enforces people to save for their old age. A nd it is this (additional) saving what not only leads, but automatically leads - provided the international capital markets are free enough - to the desired international shifting of demographic burdens.

R.O. 